\title{
Characterization of thyroid nodules in acromegalic patients
}

\author{
R. Trifanescu ${ }^{1,2}$, S. Galoiu ${ }^{1,2}$, D. Niculescu ${ }^{1,2}$, I. Baciu ${ }^{1,2}$, C. Capatina ${ }^{1,2}$, \\ S. Radian ${ }^{1,2}$, C. Poiana ${ }^{1,2}$ \\ 1 "Carol Davila" University of Medicine and Pharmacy, \\ 2 “C. I. Parhon” National Institute of Endocrinology, Bucharest, Romania
}

Background

Prevalence of thyroid nodules in acromegalic patients ranges from $34-77 \%$.

Prevalence of thyroid cancer in acromegalic patients ranges between $4-11.4 \%$. There is an increased risk of thyroid cancer in ACM vs. normal population $(\mathrm{RR}=7.2-10.21)$.

\section{Methods}

$>62$ patients with acromegaly $(16 \mathrm{M} / 46 \mathrm{~F})$ were retrospectively reviewed; 25 patients $(40.3 \%)$ were residents in iodine deficient areas; average age at diagnosis: $43.7 \pm 12.8$ years; median follow-up period: 8 years (range: 1-31 years);

$>$ GH, IGF1, TSH, FT4: chemiluminescence (Liason);

$>$ Thyroid ultrasound -volume $(\mathrm{ml})=\mathrm{d} \times \mathrm{w} \times 1 \times 0.479$;

$>$ Fine needle aspiration biopsy and citology exam in suspected nodules;

$>$ Pathology exam in patients submitted to surgery.

\section{Results}

Figure 1.

Thyroid morphology on ultrasound

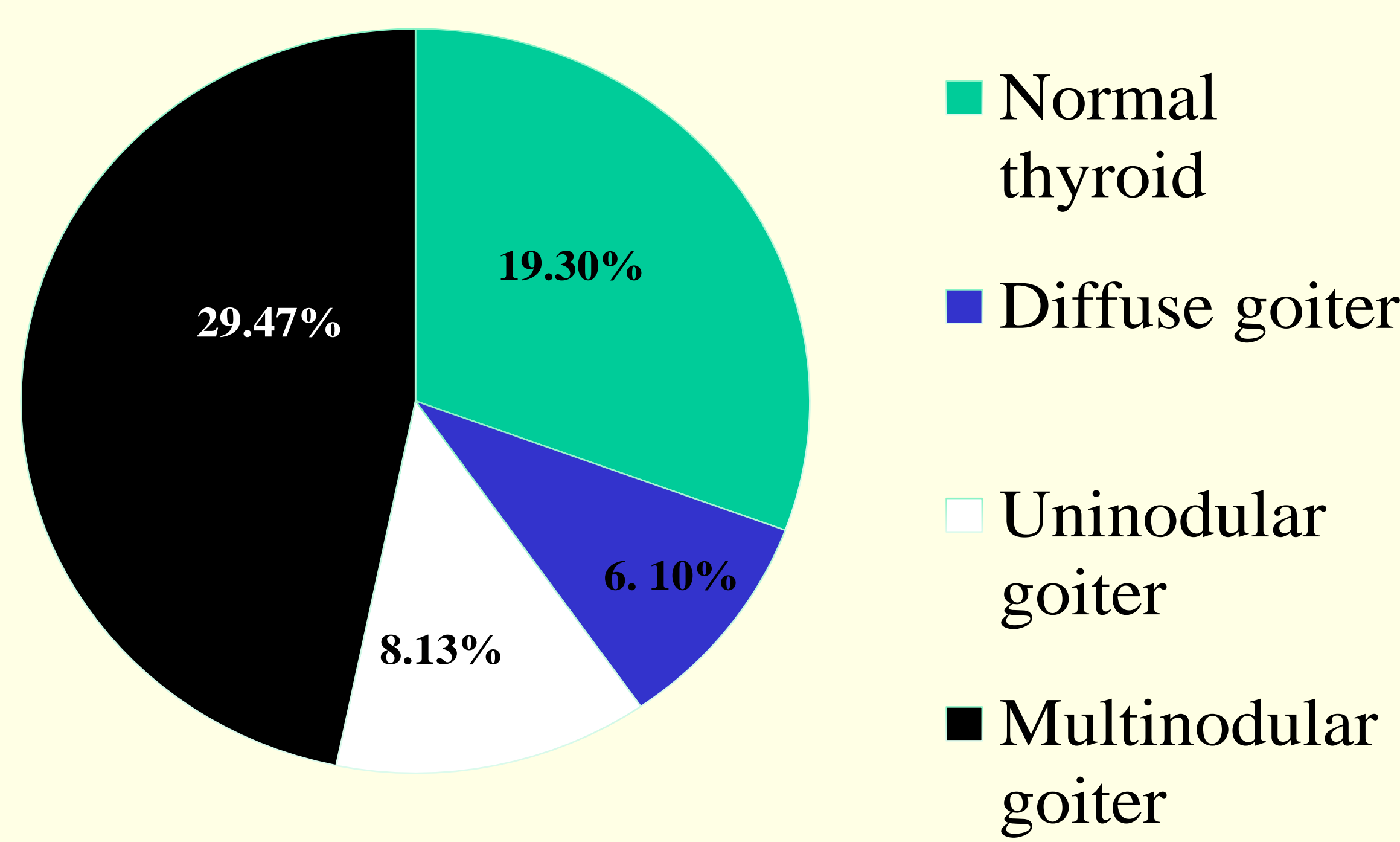

Figure 3.

IGF1 in acromegalic patients without/with thyroid nodules

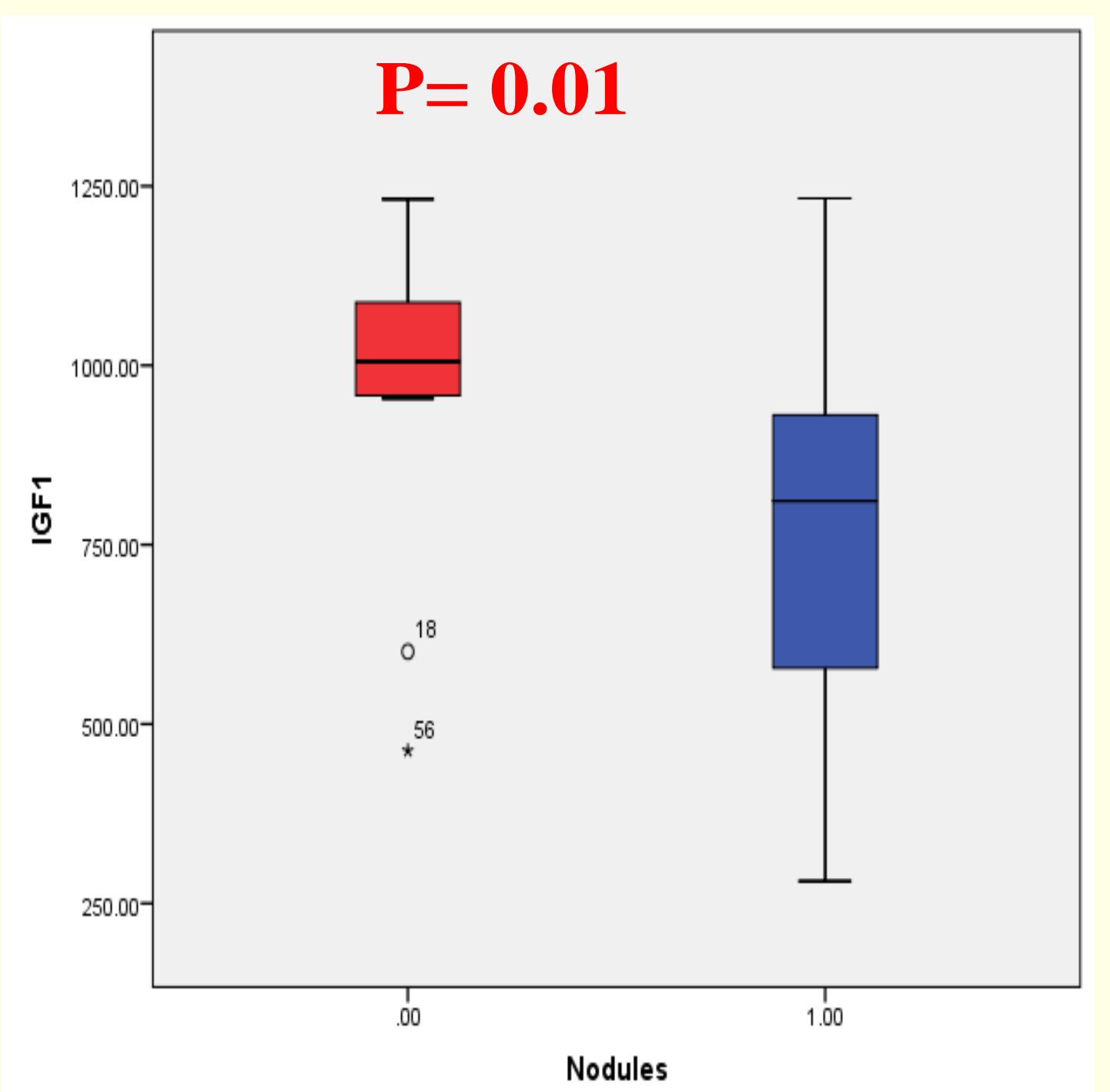

Figure 5.

BMI and TSH in thyroid carcinoma

$\mathrm{N}=6$ out of $62(9.67 \%)$

3 microcarcinomas, 3 macrocarcinomas
Figure 2.

Thyroid volume in acromegalic patients

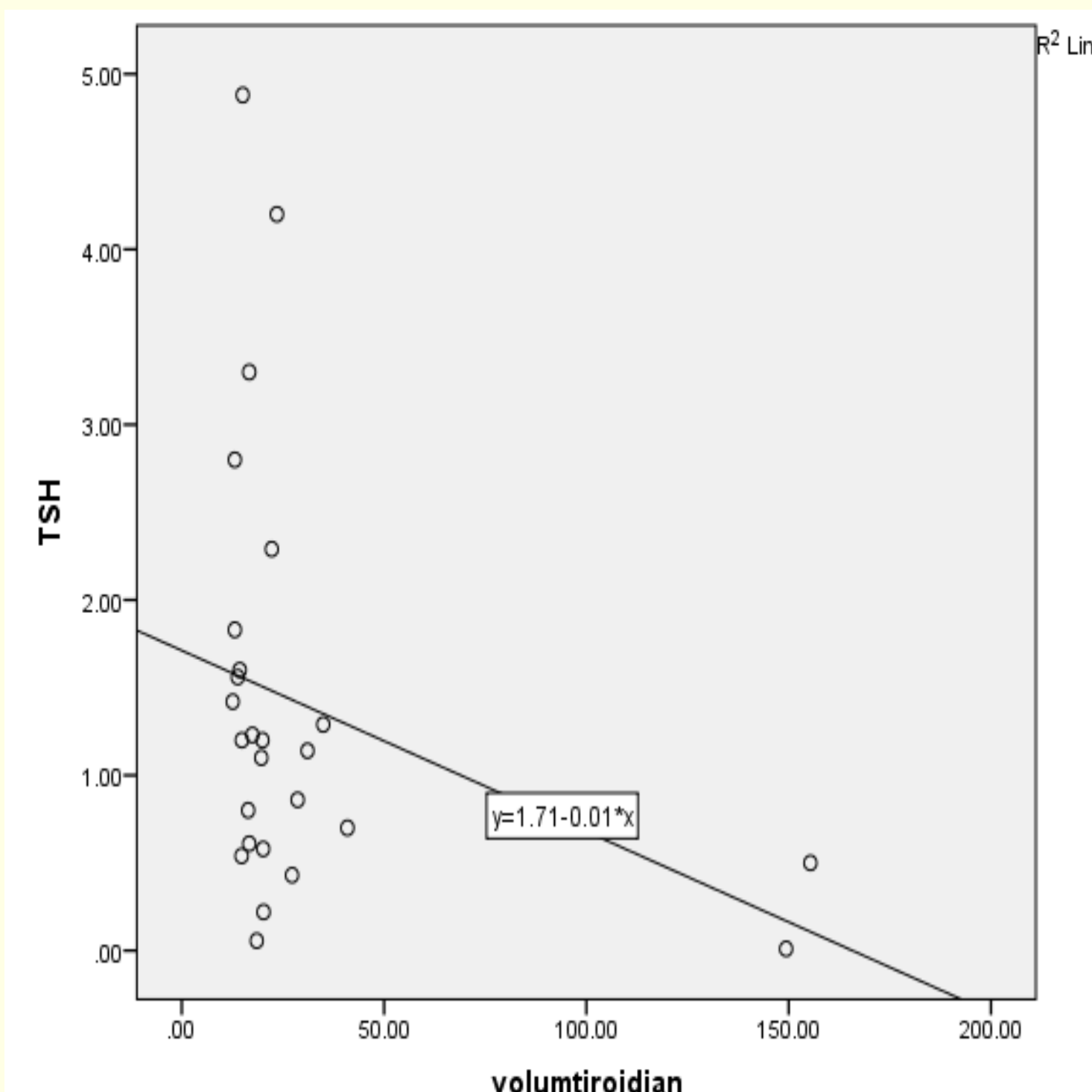

Median Thyroid volume: $19.65 \mathrm{~mL}$

$25^{\text {th }}$ percentile: $14.85 \mathrm{~mL}$

$75^{\text {th }}$ percentile: $28.6 \mathrm{~mL}$

Negative correlation with TSH: $\mathrm{r}=0.3, \mathrm{p}=0.03$

Figure 4.

TSH and thyroid volume in acromegalic patients without/with thyroid nodules

TSH
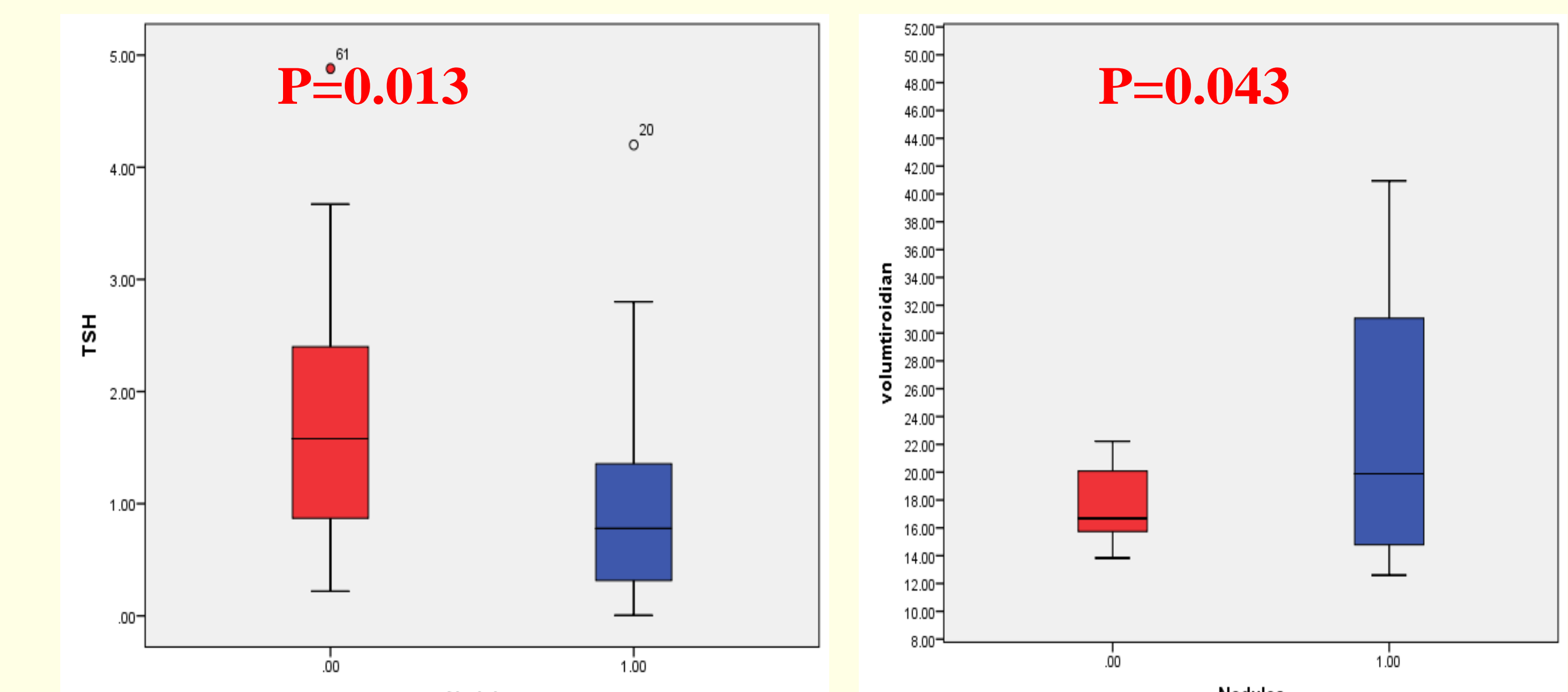

Thyroid volume
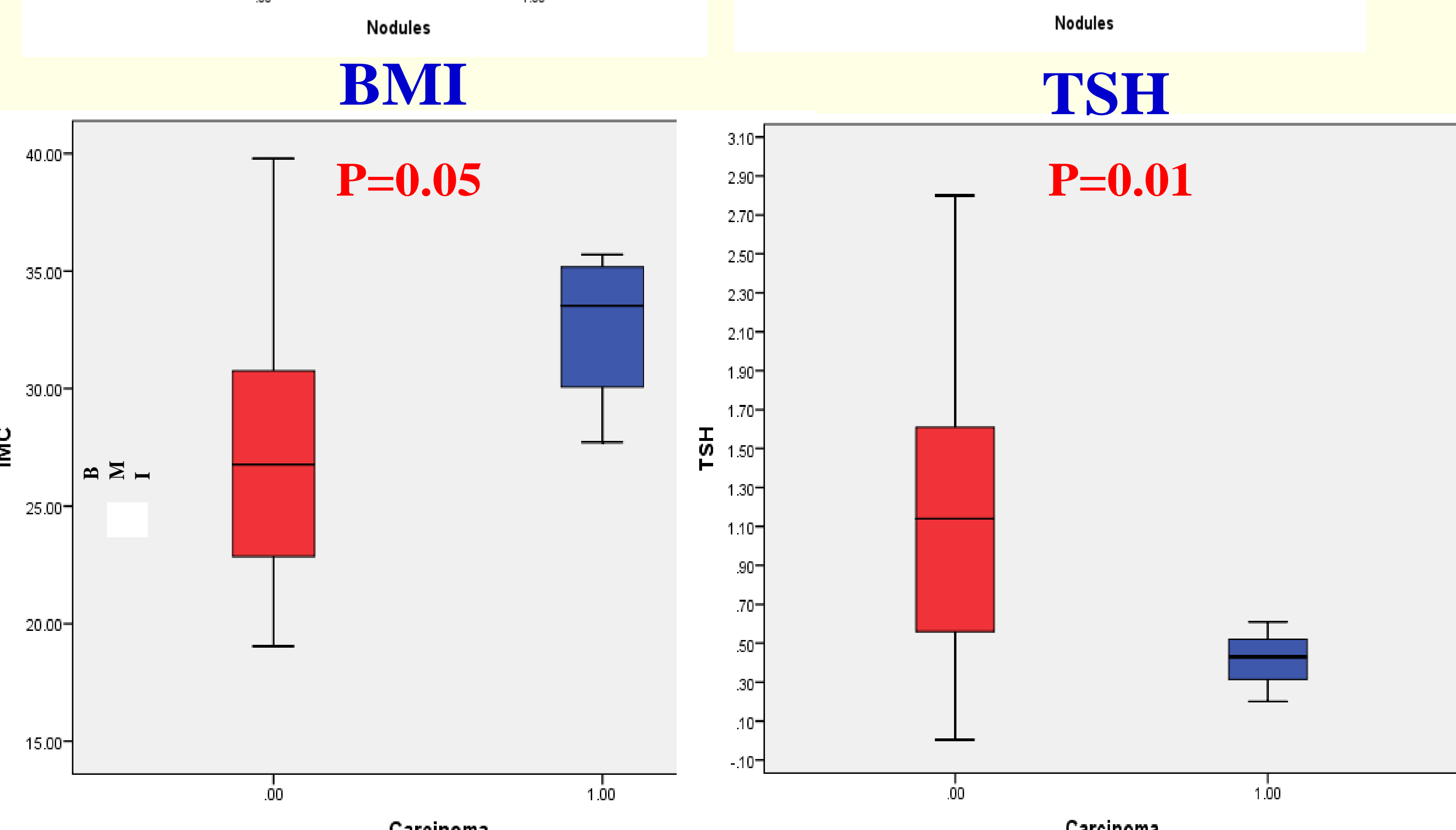

\section{Conclusions}

- thyroid nodules and differentiated thyroid carcinoma (especially papillary) had a high prevalence in acromegalic patients;

- thyroid micro-carcinomas are probably over-diagnosed among acromegalic patients due to extensive endocrine work-up;

- thyroid ultrasound and, when appropriate, fine needle aspiration are mandatory in acromegalic patients

for early diagnosis and therapeutic intervention. 